\title{
Thyroid Gland Atrophy
}

National Cancer Institute

\section{Source}

National Cancer Institute. Thyroid Gland Atrophy. NCI Thesaurus. Code C26942.

Tissue degeneration and diminished size of the thyroid gland. 